\title{
Early Warning Smartphone Diagnostics for Water Security and Analysis Using Real-Time pH Mapping
}

\author{
Md. Arafat HOSSAIN ${ }^{1,3}$, John CANNING ${ }^{1,2^{*}}$, Sandra AST ${ }^{2}$, Peter J. RUTLEDGE ${ }^{2}$, \\ and Abbas JAMALIPOUR ${ }^{3}$ \\ ${ }^{1}$ interdisciplinary Photonics Laboratories (iPL), School of Chemistry, The University of Sydney, NSW 2006, Australia \\ ${ }^{2}$ School of Chemistry, The University of Sydney, NSW 2006, Australia \\ ${ }^{3}$ Wireless Networking Group (WiNG), School of Electrical and Information Engineering, The University of Sydney, NSW \\ 2006, Australia \\ *Corresponding author: John CANNING E-mail: john.canning@sydney.edu.au
}

\begin{abstract}
Early detection of environmental disruption, unintentional or otherwise, is increasingly desired to ensure hazard minimization in many settings. Here, using a field-portable, smartphone fluorimeter to assess water quality based on the $\mathrm{pH}$ response of a designer probe, a map of $\mathrm{pH}$ of public tap water sites has been obtained. A custom designed Android application digitally processed and mapped the results utilizing the global positioning system (GPS) service of the smartphone. The map generated indicates no disruption in $\mathrm{pH}$ for all sites measured, and all the data are assessed to fall inside the upper limit of local government regulations, consistent with authority reported measurements. This implementation demonstrates a new security concept: network environmental forensics utilizing the potential of novel smartgrid analysis with wireless sensors for the detection of potential disruption to water quality at any point in the city. This concept is applicable across all smartgrid strategies within the next generation of the Internet of Things and can be extended on national and global scales to address a range of target analytes, both chemical and biological.
\end{abstract}

Keywords: Lab-in-a-phone, Internet of Things, optical sensing and sensor, smartphone sensor, photonic sensor, fluorescence, water security

Citation: Md. Arafat HOSSAIN, John CANNING, Sandra AST, Peter J. RUTLEDGE, and Abbas JAMALIPOUR, "Early Warning Smartphone Diagnostics for Water Security and Analysis Using Real-Time pH Mapping," Photonic Sensors, 2015, 5(4): 289-297.

\section{Introduction}

Regular and real-time monitoring of drinking water quality is likely to become an essential feature of urban life given the potential for natural and deliberate contamination. The disappearance of natural borders through international travel and the unexpected interdependency raised by globalisation has, in particular, raised concerns on disruption triggered remotely for remote reasons. At a more mundane level, amongst various parameters used to measure water quality, $\mathrm{pH}$ is a particularly important assessment criterion. Aligned with the World Health Organization (WHO), the Australian government's National Health and Medical Research Council (NHMRC), for example, provides a generally acceptable alkaline range of $\mathrm{pH} \sim 6.5$ to 8.5 , which avoids skin corrosion at the acidic end and irritation

Received: 12 April 2015 / Revised: 5 June 2015

(C) The Author(s) 2015. This article is published with open access at Springerlink.com

DOI: $10.1007 / \mathrm{s} 13320-015-0256-\mathrm{x}$

Article type: Regular 
of skin, eye, and mucous membranes at the basic end [1]. The NHMRC mandates for $\mathrm{pH}$ monitoring at defined frequencies both at the supplier and consumer ends, and average data is generally published on publicly accessible websites [2].

Other international agencies, such as the United States Environmental Protection Agency (EPA), are concerned with higher frequency monitoring because of the growing fear of hazardous disruption of water supplies by criminal, terrorist, military, industrial, environmental incursions [3, 4], and other as yet undefined existential threats. The existing technologies monitor daily water quality at the supplier end [4], but less frequently at the consumer end since it is practically impossible at present to assess all points of access using current methods. It seems likely the growing local and global risk of water disruption will necessitate a more frequent number of measurements than is currently undertaken. This process will be aided tremendously if the technology can be integrated into growing wireless sensor networks [5], which would allow rapid collation, detection and monitoring of propagation, and site identification and response, ideally coordinated through an automated data receiving center capable of handling and processing big data. This concept is ideal for sensor smartgrids gathering and analyzing similar data from many portable instruments and would represent a cornerstone of the next generation Internet of Things (IoT). For this purpose, cross-disciplinary activity bridging materials, photonics and electronics, and computation and networked systems are required to develop systems that would be widely applicable. Towards this goal, we have recently identified an opportunity for modern interrogation methods based on the smartphone technology, which can both expedite data collection, transmission, and analysis $[6,7]$. Here, we propose smartphone-based sensor systems that can provide this capability. Such a smartphone technology is increasingly reported recently as a field-portable platform for many applications specially in bio-diagnostic and environmental monitoring. Most of these approaches are based on simple colorimetry [8-16], imaging [17-23], and spectroscopy [24-27]. Paper microfluidic devices are sometimes integrated to the calorimetric approaches [28-35]. Smartphones are becoming cheap with rapidly increasing market share [36] and there is a capacity for each instrument to communicate with the others as well as a central data processing node. This makes them ideal for use in networked systems. Mapping of heavy metal ion detection using two parts colorimetric analysis has been reported using a smartphone [9], but this approach involves integration of two external diode sources and power supplies to image the samples, which greatly limits device accessibility for a large part of the world.

In this work, we present a fully contained "lab-in-a-phone" technology for rapid detection of any possible disruption in drinking water quality. To do this, we advance the previously reported $\mathrm{pH}$ sensor concept, which demonstrates the technology to measure environmental water [7] by upgrading both hardware and software. The lab-in-a-phone platform reported herein introduces a reference cell in the attachment to allow both direct self-referencing and calibration. The use of reference is important to avoid error addition due to time delay between sample preparation and measurement. This would allow rapid measurements and independent of time and location, which is essential for smartgrid sensing network. To advance further over our previous work, a customized Android application is reported, which digitally processes the captured images and shares results along with the GPS coordinates of the corresponding locations. This allows effective real-time mapping of a region's water quality. The work reported here establishes the potential for novel forensic tools that can analyze this data for sudden disruptions in the network, such as a change in the quality of water at 
any location. Using this technology to measure $\mathrm{pH}$, we have completed a case study of tap water across Sydney, the most common source of drinking water in this region. Many forms of disruption may push the $\mathrm{pH}$ of water outside of the recommended safe drinking levels [37], and the aim of this approach is to detect and demonstrate localization to a point of origin using mapping. Although we have reported the measurements of $\mathrm{pH}$, the concept can be extended to measure a number of other parameters with an application-specific molecular chemical or biological probe on the same platform.

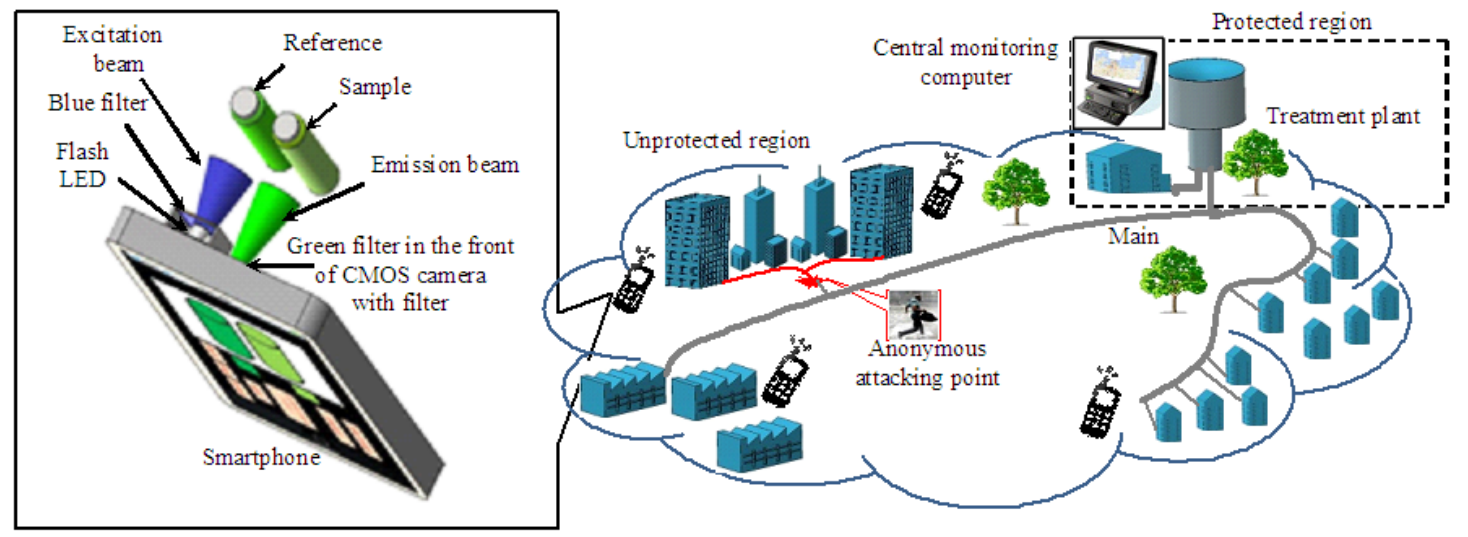

Fig. 1 Schematic on the right side demonstrating the scenario of detecting any disruption happening in the drinking water supply system with a wirelessly inter-connected smartphone system. (The schematic on the left side summarizes the principle of the smartphone fluorimeter system.)

\section{Materials and method}

The general configuration of a drinking water supply system is shown in Fig. 1, where a number of smartphone based measuring platforms are distributed across consumer locations for quickly measuring and subsequently sending the results to a central computer located at the treatment plant or elsewhere. The authority monitoring the system can map water quality to quickly find out if any disruption is occurring in the system. In contrast to this approach, previous efforts in designing chemical sensors and analyzers were aimed at in-line monitoring of water quality and are non-portable in nature $[4,5,38]$. Additionally, the high installation cost also limits the application of the existing approach across the whole system. The approach described here utilizes mostly the in-built devices of the smartphone, requiring less external components. This makes it truly portable whilst retaining smartgrid friendliness in the field.

\subsection{Device configuration}

The portable fluorimeter was deployed on an android-driven Samsung Galaxy Express (Android 4.1.2 Jelly Bean, Dual-core 1.2 GHz Krait, 5-MP camera and $480 \times 800$ pixels super active matrix organic light emitting diode (AMOLED) display) smartphone. The same fluorimeter can also be implemented on other smartphones as well as other Android driven devices, such as Tablets [39], smartwatch, Google glass [40, 41] with slight mechanical modification. The schematic summarizing the principle of the smartphone diagnostic tool is shown in Fig. 1(left). The white flash light emitting diode (LED) of the smartphone covers a wide span of emission band, $\lambda_{\mathrm{em}}=400 \mathrm{~nm}$ to $700 \mathrm{~nm}$ that can be used as an excitation source in fluorescent measurement after filtering. In this fluorimeter, the blue filtered emission peak $\left(\lambda_{\mathrm{em}}=437 \mathrm{~nm}\right)$ is used to illuminate the background of an image whilst the camera itself is the imaging sensor. However, the same LED can also be used to excite many other application specific molecular probes by selecting the filter. This extends the fluorimeters' capability further which is suitable for 
measuring multiple anatytes on the same platform rather use for a specific purpose as in [42]. However, use of this LED eliminates the need for any external sources as well as mirrors or other beam displacement hardware used in alternative smartphone based analytical systems [8-14, 17-20, 39]. This in-built source, integrated with a suitable driver circuit internally connected to the battery, has substantially greater and more consistent irradiance and is also collocated with the camera, allowing optimal illumination during imaging. In order to further improve signal-to-noise ratios over our previous work [7], a green filter is also used during fluorescence imaging to remove any background scattering of blue light, a potential source of error. The 3D structure of the smartphone attachment that contains all components (including the sample cells) was designed in Inventor software (AutoCAD) to fit over the top of the camera unit [Fig. 2(a)]. This contains a sample and reference cell chamber and suitable slots for the color filters. The attachment was then fabricated in a low-cost MakerBot Replicator 2X 3D printer [Fig. 2(b)]; the unit is robust for transport, which keeps the sample well shielded from the outside and excludes light from external sources.

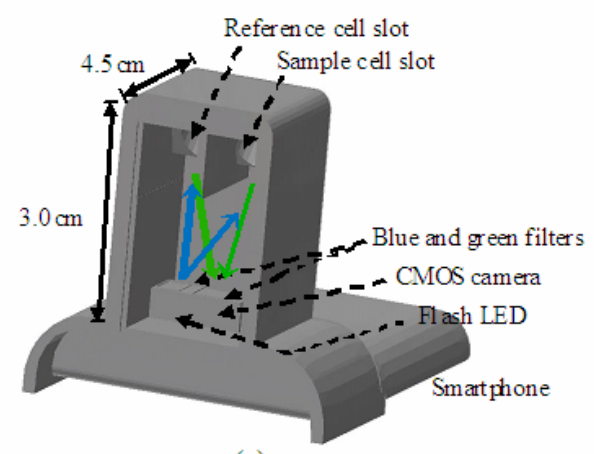

(a)

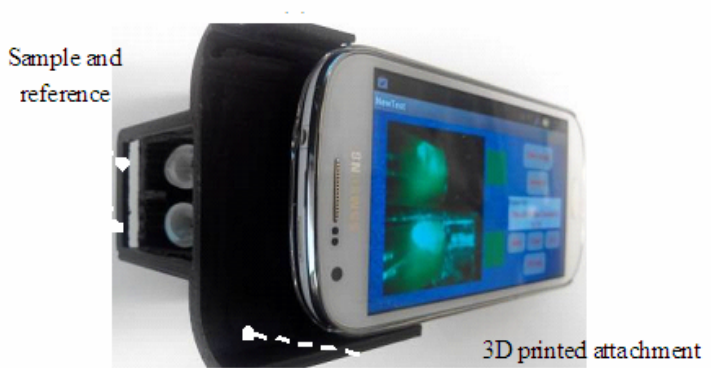

(b)

Fig. 2 Structure of the smartphone fluorimeter: (a) the smartphone attachment designed in AutoCAD Inventor Fussion, and (b) photograph of the 3D printed attachment installed on an Android -based smartphone.

\subsection{Fluorescent pH probe}

The $\mathrm{pH}$ probe used in this work is the thermally stable, easily prepared, and photo-induced electron transfer (PET) dye 4-aminonapthalimide [43]. The absorption maximum of this probe $\left(\lambda_{\mathrm{abs}} \sim 444 \mathrm{~nm}\right)$ with a $3 \mathrm{~dB}$ bandwidth of $\sim 70 \mathrm{~nm}$ aligns well with the wavelength of filtered light from the camera flash (emission peak at $\sim 437 \mathrm{~nm}$ ) [7]. The 4-aminonaphthalimide dye functions as a turn-on probe in the presence of protons (Fig. 3 inset): the protonated molecule fluoresces strongly, but with rising $\mathrm{pH}$, deprotonating of the dye leads to suppressed emission as a function of $\mathrm{pH}$ (up to $\sim \mathrm{pH}$ 10 , beyond which no further change in emission is observed). The relative fluorescence intensity of this probe across a range of $\mathrm{pH}$ with respect to a fixed $\mathrm{pH}(\sim 8.19)$ solution is plotted in Fig. 3.

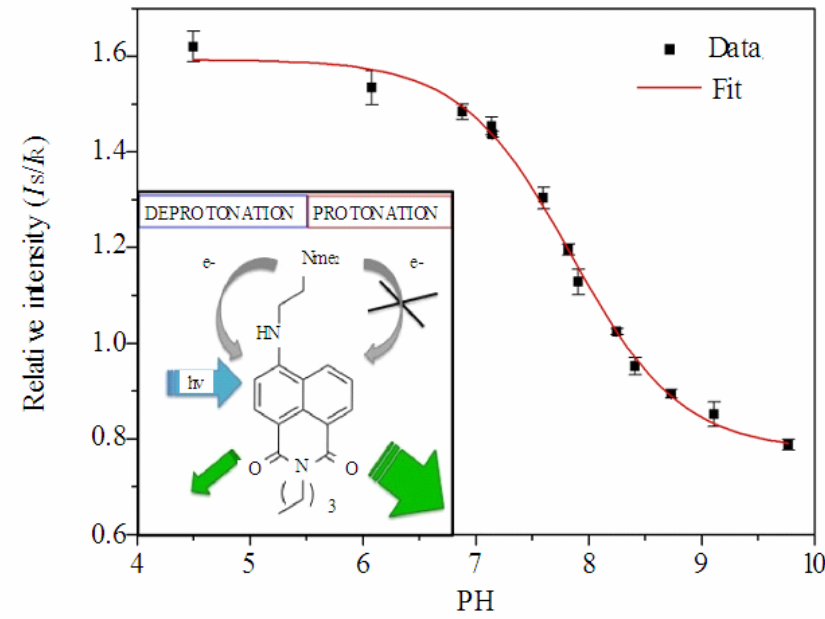

Fig. 3 Response curve of a PET type 4-aminonaphthalimide $\mathrm{pH}$ probe, 2-butyl-6-((2(dimethyl-amino)ethyl)-mino)-1Hbenzo[de]isoqinoline1,3(2H-)-dione, running on the smartphone system, (inset: fluorescence switching mechanism). [The data are fitted by a logarithmic function with a coefficient of determination (R2) of 0.998.] 


\subsection{Android-based smartphone application}

In advance to the general color analyzing app used in our previous work, a customized, user-friendly Android application was developed to allow efficient $\mathrm{pH}$ measurements of tap water in the field, and sharing of results (Fig.4). After attaching the hardware to the camera unit of the smartphone, the user can hold the phone vertically and then run the measurements with this smart application. From the main menu of the application, the user can select to start a new test, create a device-specific calibration curve, view previously run tests, and review the operating instructions. On the new test screen, after capturing the fluorescent image, the user can first preview the image on the screen

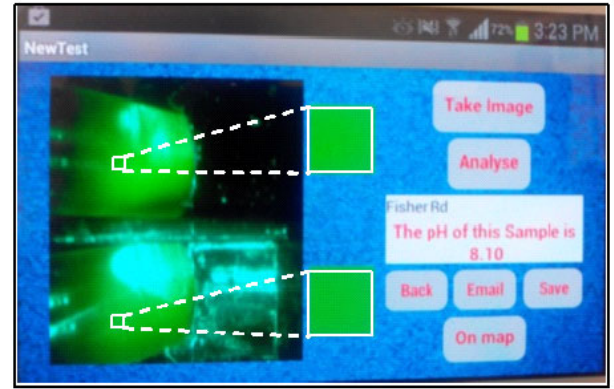

(a)

(Fig. 4(a)) before proceeding to analyze it. The algorithm was designed to compare the fluorescent green intensity in a fixed region of $20 \times 20$ pixels in the sample image with respect to that from a fixed reference solution. The screen directly shows the $\mathrm{pH}$ value of the tap water sample along with the location name. Results from various sites can be stored on the phone's available memory for mapping on the same platform as shown in Fig.4(b) or transmitted back automatically with location names and GPS coordinates to a central server for quick mapping, using, for example, a Google Maps-based interface. The GPS coordinates of a particular site is recorded automatically and sent together with the results via an e-mail option in the phone.

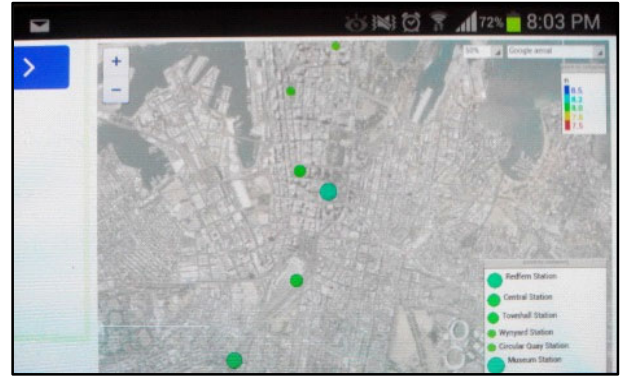

(b)

Fig. 4 Screenshots of the $\mathrm{pH}$ measurements application running on an Android phone: (a) the testing screen displaying results with location after analysis and (b) mapped with GPS coordinates on the same mobile platform (clear images are shown in Fig. 5).

\subsection{System calibration}

In order to perform the measurements of unknown $\mathrm{pH}$ using our platform, the smartphone app was first calibrated-against 13 standard samples ranging from $\mathrm{pH} 4.50$ to 9.77 with the calibration option from the main menu of the app. The samples were prepared as reported previously [7]. When all parameters (position of vials, dye concentration, volume, and excitation intensity) for both sample and the reference cell are identical, the relative fluorescence intensity can be correlated with the $\mathrm{pH}$ change in the water sample as shown in Fig. 3. When the data are fitted to the Henderson-Hasselbalch equation, the calculated acid dissociation constant ( $p K a=8.6)$ is very close to the reported values for this type of probe [43]; the small variation observed is presumably due to the different solvent system used. The calibration equation was then uploaded to the app to enable $\mathrm{pH}$ measurements of field samples.

\section{3. $\mathrm{pH}$ measurements and mapping}

Measurements of $\mathrm{pH}$ were conducted with samples from public tap water at different locations across Sydney, Australia. These included different buildings within The University of Sydney and different train stations around Sydney. In order to compare the results, the same samples were also measured with a commercial, portable $\mathrm{pH}$ meter (PHMETER, PH-035) which was calibrated with standard buffer solution before each measurement. Unlike the smartphone, this conventional system cannot be readily integrated into a wireless network and requires a distinct power supply that is not 
available at many sites globally. In contrast, the mobile fluorimeter uses the same calibration procedure each time ensuring the instrument is truly field-portable whilst providing good agreement within small experimental error.

Notably, the smartphone-based fluorimeter can also generate real-time maps within the same platform and share results with others for centralised mapping. To do this, GPS coordinates were recorded at each measurement location and saved within the phone's memory for mapping within the same device. The results were also sent wirelessly to a central computer at the interdisciplinary Photonic Laboratories ( $i \mathrm{PL})$ in The University of Sydney for quick mapping. This offers further advantages over the conventional $\mathrm{pH}$ meter, enabling direct integration into wireless sensor networks for direct access to central laboratory analysis. Figure 5 represents two $\mathrm{pH}$ maps generated from smartphone fluorimeter data sent from the recorded locations. The water within these locations is found to be slightly alkaline, with $\mathrm{pH} \sim(7.89-8.27) \pm 0.10$ and an average $\mathrm{pH}_{\mathrm{av}}=8.08 \pm 0.04$. The values are represented by a color bar as well as dot size. The map generated for this region indicates no spikes in results, reflecting the fact that there was no detected disruption of $\mathrm{pH}$ in public drinking water at The University of Sydney or City Circle train stations during the period that these measurements were made. These results are also within the upper limit of the NSW government's tolerable alkalinity $(\mathrm{pH}=8.50)$ as summarized in Table 1 and are consistent with the values recently reported for this region $\left(\mathrm{pH}_{\mathrm{av}}=8.10\right)$ [2]. In a fully implemented wireless sensor network, monitoring would be done on a regular basis and diagnostics and analysis automated at the data mapping center. The monitoring range can be extended to a national and even a global scale by collecting similar data from many portable instruments (where resources permit, supplemented by permanent analytical systems), connected to the wireless infrastructure. This approach has great potential for monitoring many other environmental analytes and for remote biological analysis on national and global scales.

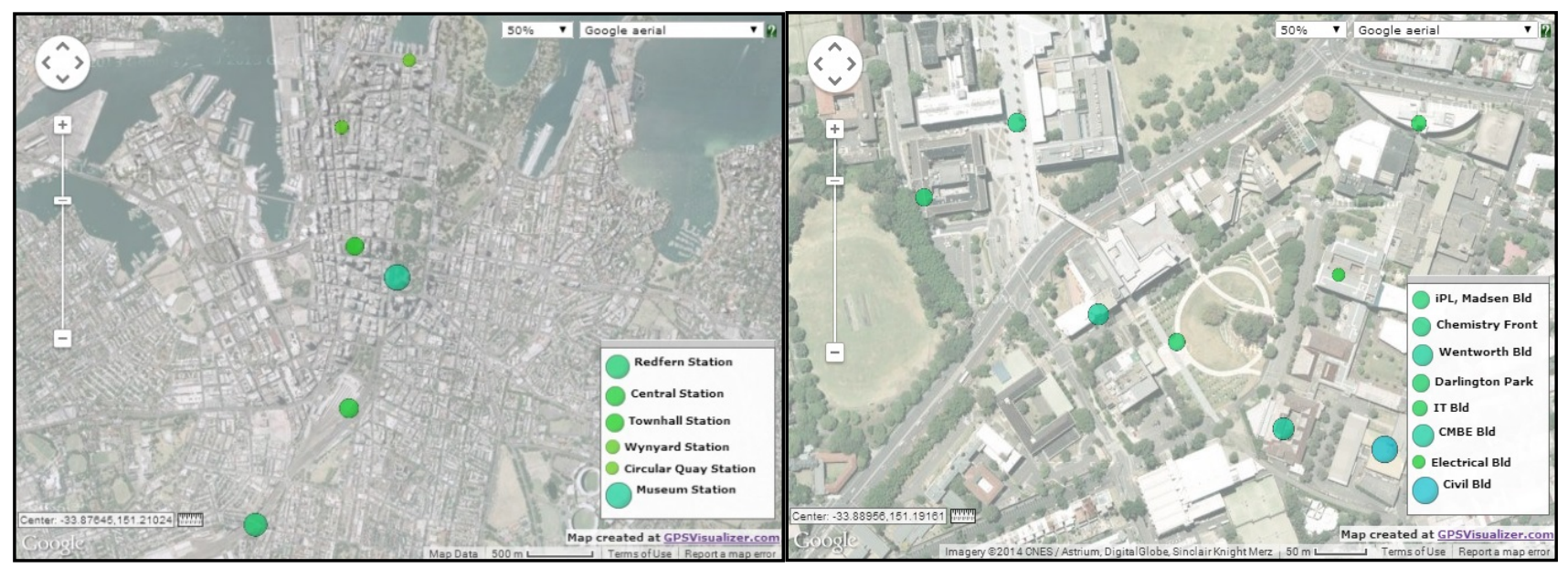

(a)

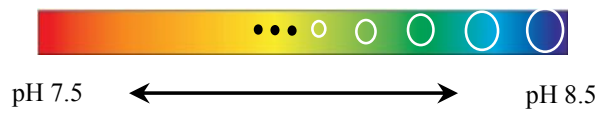

(b)

(c)

Fig. 5 Results of tap water pH mapping at (a) Sydney City Circle train stations, (b) the University of Sydney, and (c) the color gradient (in color: from red to blue) and dot size indicate the $\mathrm{pH}$ value. 
Table 1 Comparison of smartphone fluorimeter with standard $\mathrm{pH}$ meter measurements of tap water $\mathrm{pH}$ at Sydney City Circle train stations and The University of Sydney area.

\begin{tabular}{cccc}
\hline Area & Locations & Smartphone fluorimeter & $\mathrm{pH}$ meter \\
\hline \multirow{4}{*}{ Train } & Redfern & $8.02 \pm 0.02$ & 8.05 \\
stations & Central & $8.04 \pm 0.02$ & 8.15 \\
& Townhall & $8.01 \pm 0.06$ & 8.07 \\
& Wynyard & $7.91 \pm 0.05$ & 8.01 \\
& Circular Quay & $7.89 \pm 0.06$ & 8.02 \\
& Museum & $8.20 \pm 0.10$ & 8.08 \\
\hline \multirow{4}{*}{ University } & $i$ PL & $8.11 \pm 0.03$ & 8.16 \\
& Chemistry front & $8.14 \pm 0.01$ & 8.14 \\
& Wentworth Bld & $8.21 \pm 0.01$ & 8.20 \\
& Darlington Park & $8.11 \pm 0.04$ & 8.22 \\
& IT Bld & $8.08 \pm 0.05$ & 8.20 \\
& CBME Bld & $8.18 \pm 0.01$ & 8.15 \\
& EIE Bld & $8.04 \pm 0.04$ & 8.08 \\
& Civil Bld & $8.27 \pm 0.05$ & 8.23 \\
\hline
\end{tabular}

\section{Conclusions}

We have proposed a new forensic concept network and smartphone environmental forensics, where incursive disruptions and their extent can potentially be detected in real time. This approach enables water security that can take advantage of next-generation wireless sensor technologies. We have demonstrated the application of a novel smartphone-based $\mathrm{pH}$ meter to rapidly assess and map the quality of drinking water around Sydney varying locations dynamically as needed. The measured $\mathrm{pH}$ distribution is consistent at all sites with results published by official authorities using traditional technologies (and measured at fewer locations). As it was expected for the reported regions, no evidence of water supply disruption was uncovered. Nonetheless, the approach can be scaled and introduced with relative ease to increase field resolution. Combined with existing routine visits by water authority personnel and automated sensing using wireless technologies at fixed locations, this method can form the basis of an efficient passive and dynamic network mapping tool for early detection of disruptions in water health both in Australia and in more vulnerable regions of the world. The technology is an example of a broad interdisciplinary approach to integrated photonic sensor systems that are connected to an intelligent smartgrid, the fundamental underpinning of the so-called Internet of Things.

It can clearly be applied, more specifically for the detection of anticipated pathogens (such as those expected in some regions of the world) or other contaminations, like toxic metal ions and organic waste by-products, which were introduced into the ecosystem through various industrial and consumer processes.

\section{Acknowledgment}

The authors acknowledge support from the Australian Research Council (ARC) through grants ARC FT110100116 and DP120104035. Md. Arafat Hossain acknowledges an International Postgraduate Research Scholarship (IPRS) from The University of Sydney.

Open Access This article is distributed under the terms of the Creative Commons Attribution License which permits any use, distribution, and reproduction in any medium, provided the original author(s) and source are credited.

\section{References}

[1] Australian government's National Health and Medical Research Council, "Australian drinking water guidelines 6," National Water Quality Management Strategy, 2013, 2: 174.

[2] Sydney Water, Quarterly Drinking Water Quality Report, 1 Jul. 2013 to 30 Sep. 2013, Sydney, Australian: Sydney Water. www.sydneywater.com.au, 2014.

[3] P. H. Gleick, "Water and terrorism," Water Policy, 2006, 8(6): 481-503.

[4] J. S. Hall, J. G. Szabo, S. Panguluri, and G. Meiners, Distribution System Water Quality Monitoring: Sensor Technology Evaluation Methodology and Results, Cincinnati, U. S. A.: U. S. Environmental Protection Agency, 2009.

[5] J. V. Capella, A. Bonastre, R. Ors, and M. Peris, "A wireless sensor network approach for distributed in-line chemical analysis of water," Talanta, 2010, 80(5): 1789-1798.

[6] M. A. Hossain, J. Canning, S. Ast, T. L. Yen, P. J. Rutledge, and A. Jamalipour, "A smartphone fluorometer - the lab-in-a-phone," in Conference: Optical Sensor, pp. SeTh2C.1, 2014. 
[7] M. A. Hossain, J. Canning, S. Ast, P. J. Rutledge, T. L. Yen, and A. Jamalipour, "Lab-in-a-phone: smartphone-based portable fluorometer for $\mathrm{pH}$ measurements of environmental water," IEEE Sensor Journal, 2015, 15(9): 5095-5102.

[8] A. F. Coskun, J. Wong, D. Khodadadi, R. Nagi, A. Teya, and A. Ozcan, "A personalized food allergen testing platform on a cell phone," Lab Chip, 2013, 13(4): 636-640.

[9] Q. Wei, R. Nagi, K. Sadeghi, S. Feng, E. Yan, S. J. Ki, et al., "Detection and spatial mapping of mercury contamination in water samples using a smart-phone," ACS Nano, 2014, 8(2): 1121-1129.

[10] S. Sumriddetchkajorn, K. Chaitavon, and Y. Intaravanne, "Mobile-platform based colorimeter for monitoring chlorine concentration in water," Sensors and Actuators B: Chemical, 2014, 191: 561-566 2014.

[11] Y. Intaravannea, S. Sumriddetchkajorn, and J. Nukeawa, "Cell phone-based two-dimensional spectral analysis for banana ripeness estimation," Sensors and Actuators B: Chemical, 2012, 168: 390-394.

[12] A. García, M. M. Erenas, E. D. Marinetto, C. A. Abada, I. O. Paya, A. J. Palma, et al., "Mobile phone platform as portable chemical analyzer," Sensors and Actuators B: Chemical, 2011, 156(1): 350-359, 2011.

[13] Z. Iqbal and R. B. Bjorklund, "Assessment of a mobile phone for use as a spectroscopic analytical tool for foods and beverages," International Journal of Food Science \& Technology, 2011, 46(11): 2428-2436.

[14] J. Canning, A. Lau, M. Naqshbandi, I. Petermann, and M. J. Crossley, "Measurement of fluorescence in a rhodamine-123 doped self-assembled 'giant' meso-structured silica sphere using a smartphone as optical hardware," Sensors, 2011, 11(7): 70551-7062.

[15] Z. Iqbal and R. B. Bjorklund, "Colorimetric analysis of water and sand samples performed on a mobile phone," Talanta, 2011, 84(4): 1118-1123.

[16] T. S. Park and J. Y. Yoon, "Smartphone detection of escherichia coli from field water samples on paper microfluidics" IEEE Sensor Journal, 2015, 15(3): 1902-1907.

[17] D. N. Breslauer, R. N. Maamari, N. A. Switz, W. A. Lam, and D. A. Fletcher, "Mobile phone based clinical microscopy for global health applications," PLoS ONE, 2009, 4(7): e6320-1-e6320-7, 2009.

[18] Z. J. Smith, K. Chu, A. R. Espenson, A. Gryshuk, M. Molinaro, D. M. Dwyre, et al., "Cell phone-based platform for biomedical device development and education applications," PLoS ONE, 2011, 6(3): e17150-1-e17150-11.

[19] Q. Wei, H. Qi, W. Luo, D. Tseng, S. J. Ki, Z. Wan, et al., "Fluorescent imaging of single nanoparticles and viruses on a smart phone," ACS Nano, 2013, 7(10): 9147-9155.

[20] A. Skandarajah, C. D. Reber, N. A. Switz, and D. A. Fletcher, "Quantitative imaging with a mobile phone microscope," PLoS ONE, 2014, 9(5): e96906-1-e96906-12.

[21] S. Lee and C. Yang, "A smartphone-based chip-scale microscope using ambient illumination," Lab Chip, 2014, 14(16): 3056-3063.

[22] H. C. Koydemir, Z. Gorocs, D. Tseng, B. Cortazar, S. Feng, R. Y. L. Chan, et al., "Rapid imaging, detection and quantification of Giardia lamblia cysts using mobile-phone based fluorescent microscopy and machine learning," Lab Chip, 2015, 15(5): 1284-1293.

[23] S. K. J. Ludwig, H. Zhu, S. Phillips, A. Shiledar, S. Feng, D. Tseng, et al., "Cellphone-based detection platform for rbST biomarker analysis in milk extracts using a microsphere fluorescence immunoassay," Analytical and Bioanalytical Chemistry, 2014, 406(27): 6857-6866.

[24] D. Gallegos, K. D. Long, H. Yu, P. P. Clark, Y. Lin, S. George, et al., "Label-free bio-detection using a smartphone," Lab Chip, 2013, 13(11): 2124-2132.

[25] H. Yu, Y. Tan, and B. T. Cunningham, "Smartphone fluorescence spectroscopy," Analytical Chemistriy, 2014, 86(17): 8805-8813.

[26] S. Dutta, A. Choudhury, and P. Nath, "Evanescent wave coupled spectroscopic sensing using smartphone," IEEE Photonics Technology Letters, 2014, 26(6): 568-570.

[27] M. A. Hossain, J. Canning, S. Ast, K. Cook, P. J. Rutledge, and A. Jamalipour, "Combined 'dual' absorption and fluorescent smartphone spectrometers," Optics Letters, 2015, 40(8): 1737-1740.

[28] A. W. Martinez, S. T, Phillips, E. Carrilho, S. W. Thomas, H. Sindi, and G. M. Whitesides, "Simple telemedicine for developing regions: camera phones and paper-based microfluidic devices for real-time, off-site diagnosis," Analytical Chemistriy, 2008, 80(10): 3699-3707.

[29] L. Shen, J. A. Hagan, and I. Papautsky, "Point-of-care colorimetric detection with a smartphone," Lab Chip, 2012, 12(21): 4240-4243.

[30] J. I. Hong and B. Y. Chang, Development of "Smartphone-based colorimetry for multi-analyte sensing arrays," Lab Chip, 2014, 14(10): 1725-1732.

[31] J. E. Smith, D. K. Griffin, J. K. Leny, J. A. Hagen, J. L. Chávez, and N. K. Loughnane, "Colorimetric 
detection with aptamer-gold nanoparticle conjugates coupled to an android based color analysis application for use in the field," Talanta, 2014, 121: 247-255.

[32] O. M. Mancuso and D. Erickson, "Cholesterol testing on a smartphone," Lab Chip, 2014, 14(4): 759-763.

[33] N. S. K. Gunda, S. Naicker, S. Shinde, S. Kimbahune, S. Shrivastava, and S. Mitra, "Mobile water kit (MWK): a smartphone compatible low-cost water monitoring system for rapid detection of total coliform and E. coli," Analytical Methods, 2014, 6(16): 62361-6246.

[34] D. Erickson, D. O'Dell, L. Jiang, V. Oncescu, A. Gumus, S. Lee, et al., "Smartphone technology can be transformative to the deployment of lab-on-chip diagnostics," Lab Chip, 2014, 14(17): 3159-3164.

[35] T. S. Park, C. Baynes, S. I. Cho, and J. Y. Yoon, "Paper microfluidics for red wine tasting," RSC Advance, 2014, 4(46): 24356-24362.

[36] International Telecommunication Union, Mobile-cellular subscriptions 2013, Available online: http://www.itu.int/en/ITU-D/Statistics, 2015.

[37] B. Oram, Water Research Centre, Available online: http://www.water-research.net/index.php/ph-in-the-e nvironment.mm, 2014.
[38] J. Buffle and G. Horvai, In situ monitoring of aquatic systems: chemical analysis and speciation. New York, U. S. A.: Willey, 2000.

[39] J. Canning, M. Naqshbandi, and M. J. Crossley, "Measurement of rhodamine B absorption in self-assembled silica microwires using a Tablet as the optical source," in Proc. SPIE, vol. 8351, pp. 83512E-1-83512E -5, 2012.

[40] S. Feng, R. Caire, B. Cortazar, M. Turan, A. Wong, and A. Ozcan "Immunochromatographic diagnostic test analysis using Google Glass," ACS Nano, 2014, 8(3): 3069-3079.

[41] B. Cortazar, H. C. Koydemir, D. Tseng, S. Feng, and A. Ozcan, "Quantification of plant chlorophyll content using google glass," Lab Chip, 2015, 15(7): 1708-1716.

[42] Sesorex, SAM-1 for iPhone, iPad and Android, Avialable online: http://www.sensorex.com/products /more/sam_1, 2015.

[43] A. P. D. Silva, H. Q. N. Gunaratne, J. L. Habib-Jiwan, C. P. McCoy, T. E. Rice, and J. P. Soumillion, "New fluorescent model compounds for the study of photoinduced electron transfer: the influence of a molecular electric field in the excited state," Angewandte Chemie International Edition, 1995, 34(16): 1728-1731. 